\title{
Activation of Galectin-3 (LGALS3) Transcription by Injurious Stimuli in the Liver Is Commonly Mediated by BRG1
}

\author{
Zilong Li ${ }^{3 \dagger}$, Fangqiao $\mathrm{Lv}^{4 \dagger}$, Congxin Dai ${ }^{5}$, Qiong Wang ${ }^{1}$, Chao Jiang ${ }^{1 *}$, Mingming Fang ${ }^{2,6 *}$ \\ and Yong $\mathrm{Xu}^{3,6}$
}

1 Department of Surgical Oncology, the Affiliated Hospital of Nanjing University of Chinese Medicine, Jiangsu Province Hospital of Traditional Chinese Medicine, Nanjing, China, ${ }^{2}$ Department of Clinical Medicine, Laboratory Center for Basic Medical Sciences, Jiangsu Health Vocational College, Nanjing, China, ${ }^{3}$ Key Laboratory of Targeted Intervention of Cardiovascular Disease and Collaborative Innovation Center for Cardiovascular Translational Medicine, Department of Pathophysiology, Nanjing Medical University, Nanjing, China, ${ }^{4}$ Department of Cell Biology, School of Basic Medical Sciences, Capital Medical University, Beijing, China, ${ }^{5}$ Department of Neurosurgery, Peking Union Medical College Hospital, Beijing, China, ${ }^{6}$ Institute of Biomedical Research, Liaocheng University, Liaocheng, China

\section{OPEN ACCESS}

Edited by:

Mario Antonio Bianchet, Johns Hopkins University,

United States

Reviewed by:

Rohini Muthuswami, Jawaharlal Nehru University, India Gerardo R. Vasta, University of Maryland, Baltimore, United States

*Correspondence: Chao Jiang doctorjc@163.com

Mingming Fang dafeifang@163.com

tThese authors have contributed equally to this work

Specialty section:

This article was submitted to

Molecular Medicine,

a section of the journal

Frontiers in Cell and Developmental

Biology

Received: 19 August 2019 Accepted: 13 November 2019 Published: 26 November 2019

Citation:

Li Z, Lv F, Dai C, Wang Q Jiang C, Fang $M$ and $X u Y(2019)$ Activation of Galectin-3 (LGALS3)

Transcription by Injurious Stimuli

in the Liver Is Commonly Mediated by

BRG1. Front. Cell Dev. Biol. 7:310.

doi: 10.3389/fcell.2019.00310
Galectin-3 (encoded by LGALS3) is a glycan-binding protein that regulates a diverse range of pathophysiological processes contributing to the pathogenesis of human diseases. Previous studies have found that galectin-3 levels are up-regulated in the liver by a host of different injurious stimuli. The underlying epigenetic mechanism, however, is unclear. Here we report that conditional knockout of Brahma related gene (BRG1), a chromatin remodeling protein, in hepatocytes attenuated induction of galectin-3 expression in several different animal models of liver injury. Similarly, BRG1 depletion or pharmaceutical inhibition in cultured hepatocytes suppressed the induction of galectin-3 expression by treatment with LPS plus free fatty acid (palmitate). Further analysis revealed that BRG1 interacted with $\mathrm{AP}-1$ to bind to the proximal galectin-3 promoter and activate transcription. Mechanistically, DNA demethylation surrounding the galectin-3 promoter appeared to be a rate-limiting step in BRG1-mediated activation of galectin-3 transcription. BRG1 recruited the DNA 5-methylcytosine dioxygenase TET1 to the galectin-3 to promote active DNA demethylation thereby activating galectin-3 transcription. Finally, TET1 silencing abrogated induction of galectin-3 expression by LPS plus palmitate in cultured hepatocytes. In conclusion, our data unveil a novel epigenetic pathway that contributes to injury-associated activation of galectin-3 transcription in hepatocytes.

Keywords: transcriptional regulation, epigenetics, liver injury, hepatocytes, DNA demethylation

\section{INTRODUCTION}

Transcriptional regulation in mammalian cells is acutely influenced by the epigenetic machinery, which includes DNA and histone modifying enzymes, chromatin remodeling proteins, and non-coding regulatory RNAs (Ledford, 2015). DNA is wrapped around histone octamers (nucleosomes) to form higher-order chromatins serving as basic transcription unit. A host of chemical groups are superimposed on DNA and histone tails (thus the prefix "epi-") creating a layer of regulatory information (Shafabakhsh et al., 2019). Creation, maintenance, and recognition of this regulatory layer are coordinately mediated by the 
aforementioned epigenetic factors to dictate specific transcriptional events and program pathophysiological processes. Typically, chromatins can be categorized into three groups based on characteristic DNA/histone modifications associated with the promoter region (Lennartsson and Ekwall, 2009). Actively transcribed chromatins are marked by high levels of histone $\mathrm{H} 3$ acetylation and $\mathrm{H} 3 \mathrm{~K} 4$ trimethylation. On the contrary, silenced chromatin regions are demarcated by high levels of DNA methylation (CpG) and histone H3K9/H3K27 methylation. The third group of chromatins possess both the "active" and the "repressive" DNA/histone markers and therefore can be said to be labeled by "bivalent" modifications; removal of the "repressive" modifications potentiates transcription whereas erasure of the "active" modifications permanently turns off transcription (Harikumar and Meshorer, 2015).

Brahma related gene (BRG1) is the core component of the mammalian SWI/SNF chromatin remodeling complex (Wu $\mathrm{H}$. et al., 2017). Along with its closely related sibling Brahma (BRM), BRG1 provides the ATPase activity to furrow the nucleosomes (Reisman et al., 2009). BRG1 contains a bromodomain that recognizes acetylated histones and helps tether BRG1 to the chromatin although locus-specific recruitment of BRG1 is determined by sequence-specific transcription factors (Ptashne, 2007, 2013). In addition to its role as a fueling force for nucleosomal mobilization, BRG1 can regulate transcription independent of its ATPase activity (Chaiyachati et al., 2013). Mounting evidence suggests that there are extensive dialogues between BRG1 and other branches of the epigenetic machinery. For instance, long non-coding RNAs (lncRNAs) can interact with BRG1 and modulate BRG1 activity (Leisegang et al., 2017; Chen et al., 2018; Huang et al., 2019). BRG1 has also been shown to form crosstalk with histone acetyltransferases/deacetylases, histone methyltransferases/demethylases, and DNA methyltransferases/demethylases (Pal et al., 2004; Naidu et al., 2009; Yildirim et al., 2011; Xiao et al., 2016; Zhang et al., 2018; Shao et al., 2019). Owing to its pivotal role in transcriptional regulation, BRG1 deficiency causes developmental arrest and premature death during embryogenesis (Bultman et al., 2000, 2005; Griffin et al., 2008, 2011). There is emerging evidence that aberrant activation of BRG1 may result in the pathogenesis of a host of human diseases including atherosclerosis (Fang et al., 2013), pulmonary arterial hypertension (Chen et al., 2013), non-alcoholic steatohepatitis (Tian et al., 2013), cardiac hypertrophy (Hang et al., 2010), and cancers (Wu Q. et al., 2017).

Galectin-3, encoded by LGALS3, belongs to a family of glycan-binding proteins regulating such fundamental cellular functions as proliferation, migration, differentiation, apoptosis, and inflammation (Sciacchitano et al., 2018). Galectin-3 exhibits a ubiquitous expression pattern in adults under physiological conditions. When exposed to injurious stimuli, expression of galectin-3 can be altered in a cell type and signal-specific manner indicating it may serve as an "alarmin" that mediates cellular stress responses. For instance, it has previously been reported that hepatic galectin-3 expression is up-regulated in different animal models of liver injury but the underlying epigenetic mechanism remains underappreciated (Henderson et al., 2006; Dragomir et al., 2012b; Pejnovic et al., 2013; Locatelli et al., 2014;
Jeftic et al., 2015). Here we report that activation of galectin3 transcription by different injurious stimuli in the liver shares a common mediator in BRG1. BRG1 directly binds to the galectin-3 promoter by interacting with AP-1 and recruits the DNA demethylase (dioxygenase) TET1 to activate galectin3 transcription.

\section{MATERIALS AND METHODS}

\section{Animals}

All animal experiments were reviewed and approved by the intramural Ethics Committee on Humane Treatment of Experimental Animals. The breedings were conducted by Nanjing Biomedical Research Institute of Nanjing University. Hepatocyte conditional BRG1 knockout (CKO) mice were obtained by crossing the Smarca4 ${ }^{\mathrm{f} / \mathrm{f}}$ mice (Eroglu et al., 2006) with the $A l b$-Cre mice (Jackson Laboratory). To induce liver injury, $6 \sim 8$ week male mice were fasted overnight before receiving a single injection of APAP (Sigma) at $300 \mathrm{mg} / \mathrm{kg}$. Alternatively, $6 \sim 8$ week male mice were given a single injection of $\mathrm{CCl}_{4}(1.0 \mathrm{~mL} / \mathrm{kg}$ body weight as $50 \%, \mathrm{vol} / \mathrm{vol})$ as previously described (Li et al., 2018a). To induce steatotic injury, 8 weekold male were fed a methionine- and choline-deficient (MCD) diet (A02082002B, Research Diets) for eight consecutive weeks as previously described (Liu et al., 2019a). Alternatively, the mice were fed on a high-fat diet (HFD, D12492, Research Diets) for 16 weeks as previously described ( $\mathrm{Li}$ et al., 2018b). To silence BRG1 in $d b / d b$ mice, the mice were injected via tail vein purified lentiviral particles $\left(1 \times 10^{9} \mathrm{MOI}\right)$ that carry short hairpin RNA (shRNA) targeting Brg1 (GCUGGAGAAGCAGCAGAAG) as previously described (Tian et al., 2013).

\section{Cell Culture, Plasmids, Transient Transfection, and Reporter Assay}

Primary mouse hepatocytes were isolated and maintained as previously described (Fan et al., 2017). HepG2 cells were maintained in DMEM supplemented with 10\% FBS. FLAGtagged BRG1 (Li et al., 2018e) and LGALS3 promoterluciferase constructs (Kadrofske et al., 1998) have been described previously. LPS $(1 \mu \mathrm{g} / \mathrm{ml})$ and palmitate $(0.4 \mathrm{mM})$ were purchased from Sigma. Small interfering RNAs were purchased from Dharmacon. Transient transfection was performed with Lipofectamine 2000. Briefly, cells were plated in 12-well culture dishes $(\sim 60,000$ cells/well). The next day, $0.1 \mu \mathrm{g}$ of reporter construct and $0.1-0.3 \mu \mathrm{g}$ of effector construct were transfected into each well. DNA content was normalized by the addition of an empty vector (pcDNA3). For monitoring transfection efficiency and for normalizing luciferase activity, $0.02 \mu \mathrm{g}$ of GFP construct was transfected into each well. Cells were harvested 48 hours after transfection and reporter activity was measured using a luciferase reporter assay system (Promega) as previously described (Liu et al., 2018). All experiments were repeated three times.

\section{RNA Isolation and Real-Time PCR}

RNA was extracted with the RNeasy RNA isolation kit (Qiagen). Reverse transcriptase reactions were performed as previously 
described using a SuperScript First-strand Synthesis System (Invitrogen) (Zeng et al., 2018). Real-time qPCR reactions were performed in triplicate wells on an ABI StepOnePlus (Life Tech). The relative quantification for a given gene was normalized by the Gapdh mRNA values. All experiments were repeated three times.

\section{Protein Extraction, Immunoprecipitation, and Western Blotting}

Whole cell lysates were obtained by re-suspending cell pellets in RIPA buffer with freshly added protease inhibitor tablet (Roche). Immunoprecipitation was performed essentially as previously described (Yang et al., 2018). Briefly, anti-Brg1 (Santa Cruz, sc-17796), or pre-immune IgGs (P.I.I.) were added to and incubated with cell lysates overnight before being absorbed by Protein A/G-plus Agarose beads (Santa Cruz). Precipitated immune complex was released by boiling with $1 X$ SDS electrophoresis sample buffer. Western analyses were performed with anti- $\beta$-actin (Sigma), anti-Brg1 (Santa Cruz, sc-17796), anti-TET1 (Active Motif, 61443), anti-c-Jun (Santa Cruz, sc-1694), anti-c-Fos (Santa Cruz, sc-52), or anti-Galectin-3 (Proteintech, 14979-1). Uncropped full blots are included in the Supplementary Material (Supplementary Figures S1-S4).

\section{Chromatin Immunoprecipitation (ChIP)}

Chromatin immunoprecipitation assays were performed essentially as described before (Li et al., 2017, 2018c,d, 2019b; Yu et al., 2017, 2018; Fan et al., 2019; Kong et al., 2019a,b; Liu et al., 2019b; Weng et al., 2019; Yang et al., 2019a,b; Zhang et al., 2019). In brief, chromatin in control and treated cells were cross-linked with $1 \%$ formaldehyde. Cells were incubated in lysis buffer (150 mM NaCl, $25 \mathrm{mM}$ Tris $\mathrm{pH} 7.5,1 \%$ Triton X-100, 0.1\% SDS, $0.5 \%$ deoxycholate) supplemented with protease inhibitor tablet and PMSF. DNA was fragmented into $\sim 500$ bp pieces using a Branson 250 sonicator. Aliquots of lysates containing $200 \mu \mathrm{g}$ of protein were used for each immunoprecipitation reaction with the following antibodies: anti-Brg1 (Santa Cruz, sc-17796), anti-acetyl histone H3 (Millipore, 06-599), antitrimethyl H3K4 (Millipore, 07-473), anti-dimethyl H3K9 (Millipore, 07-441), anti-5'-hydroxymethylcytosine (Abcam, ab106918), anti-5'-methylcytosine (Abcam, ab10805), antiTET1 (Active Motif, 61443), anti-TET2 (Millipore, MABE462), anti-TET3 (ABE290), anti-c-Jun (Santa Cruz, sc-1694), antic-Fos (Santa Cruz, sc-52), or IgG. Precipitated DNA was amplified with the following primers: for $L G A L S 3$ promoter $(-402 /-73), \quad 5^{\prime}$-AATTTGTAGTCAGTTCCCTAG-3' ${ }^{\prime}$ and $5^{\prime}$ AAATACTCCCAGCCCCGC-3; for LGALS3 promoter (-1276/-959), 5'-ATACCTGGTTTTCTCCATAG-3' and 5'-ATATTGCCTATAAGCTACCC-3'.

\section{Statistical Analysis}

Data are presented as mean \pm SEM. For experiments concerning multiple groups, one-way ANOVA with post hoc Scheffe analyses were performed to evaluate the differences using an SPSS package (IBM analytics). The differences between two (control and experimental) groups were determined by two-sided, unpaired Student's $t$-test.

\section{RESULTS}

\section{BRG1 Regulates Injury Induced Galectin-3 Up-Regulation in the Liver}

It has previously been demonstrated that hepatic galectin-3 expression is up-regulated in different animal models of liver injury (Henderson et al., 2006; Dragomir et al., 2012b; Pejnovic et al., 2013; Locatelli et al., 2014; Jeftic et al., 2015). On the other hand, we have shown that BRG1 deficiency attenuates liver injuries induced by toxin (Li et al., 2019a), drug overdose (Li et al., 2018a), or diet (Kong et al., 2018; Li et al., 2018b; Liu et al., 2019a) in mice. We hypothesized that BRG1 might play a role in regulating galectin-3 expression. To test this hypothesis, hepatocyte conditional BRG1 knockout (CKO) mice and wild type (WT) mice were subjected to different treatments of liver injury. In the first model, weekly injection of $\mathrm{CCl}_{4}$ was administered for 6 weeks. Hepatic galectin-3 expression was significantly up-regulated in $\mathrm{CCl}_{4}$-injected mice at the mRNA (Figure 1A) and protein (Figure 1B) levels; galectin-3 induction was less robust in $\mathrm{CKO}$ mice than in WT mice. In the second model, the mice were injected with a single dose of acetaminophen (APAP) to induce acute liver injury. APAP injection resulted in significant upregulation of galectin-3 expression in both WT and CKO mice although CKO mice displayed more modest up-regulation of galectin-3 (Figures 1C,D).

Next, we exploited two different models of diet-induced steatotic injury. BRG1 deficiency compromised galectin-3 induction by MCD diet feeding (Figures 1E,F) or HFD diet feeding (Figures 1G,H). Lastly, we examined the effect of BRG1 deficiency on galectin-3 expression in a genetically predisposed model of steatotic injury. ShRNA mediated knockdown of BRG1 in $d b / d b$ mice suppressed galectin-3 expression compared to the control $d b / d b$ mice (Figures 1I,J). Thus, it appears that induction of galectin-3 by injurious stimuli in the liver may share a common mediator.

\section{BRG1 Regulates Galectin-3 Up-Regulation in Cultured Hepatocytes}

Galectin-3 has been shown to be primarily expressed in macrophages and the epithelium under physiological conditions but can be up-regulated in a wide range of cell types under pathological conditions (Chiariotti et al., 2002). To further verify whether galectin-3 expression may be up-regulated in hepatocytes exposed to injurious cues, primary hepatocytes were isolated from the mice before and after the exposure to various injurious stimuli. BRG1 deficiency attenuated galectin3 induction by either $\mathrm{CCl}_{4}$ injection (Figures 2A,B) or APAP injection (Figures 2C,D) in hepatocytes.

The various mouse models of liver injuries as described above differ significantly in etiology and pathogenesis. Inflammatory response as a result of activation of the innate immune system and increased serum free fatty acid levels due to a combination of augmented lipolysis and impaired $\beta$-oxidation can be said to be common to all these animal models (Stern et al., 1965; Begriche et al., 2011; Sandhir et al., 2017; Strazzabosco et al., 2018; 


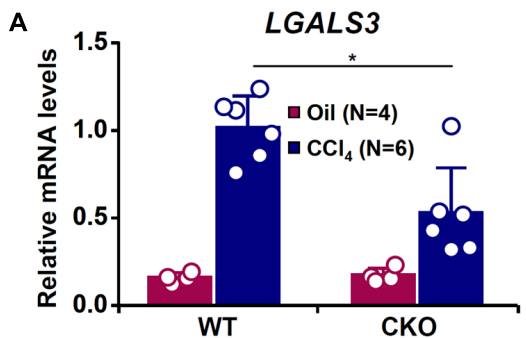

C

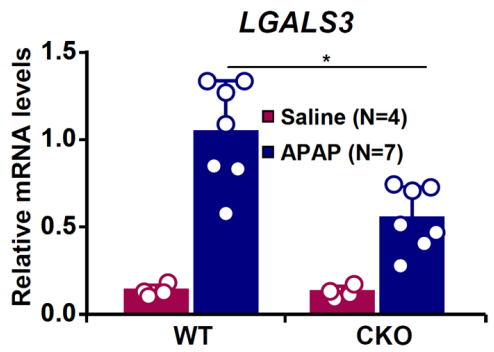

E

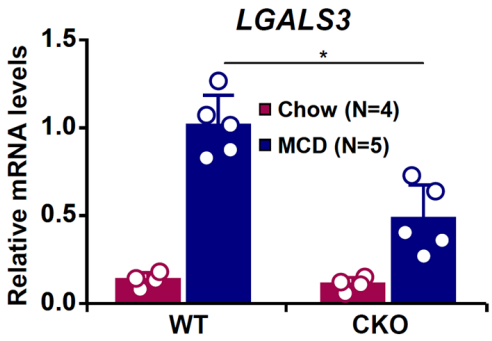

G

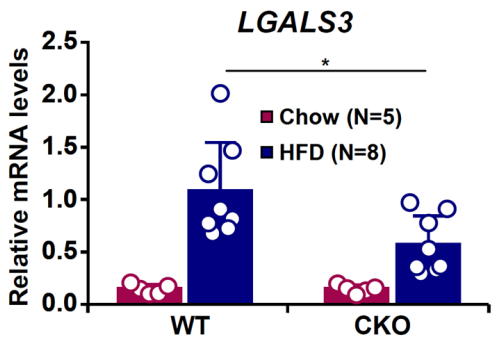

I

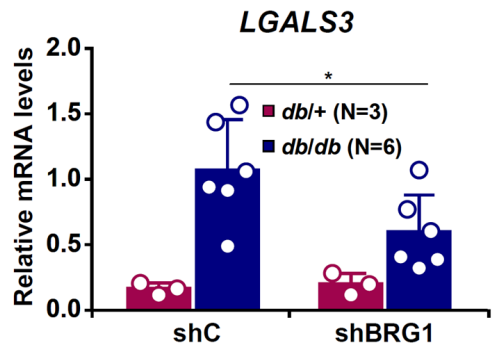

B

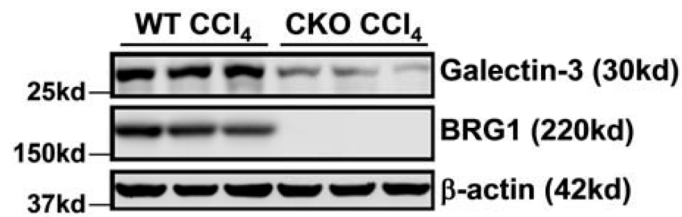

D

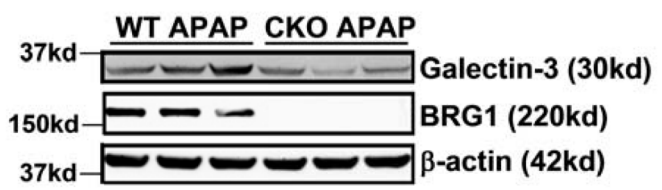

$\mathbf{F}$

H

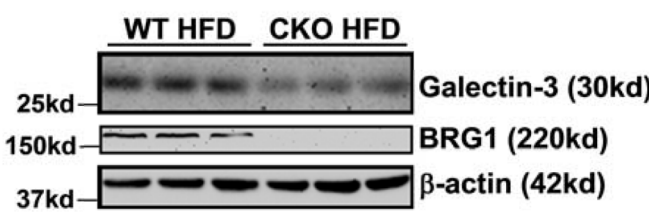

$\mathbf{J}$

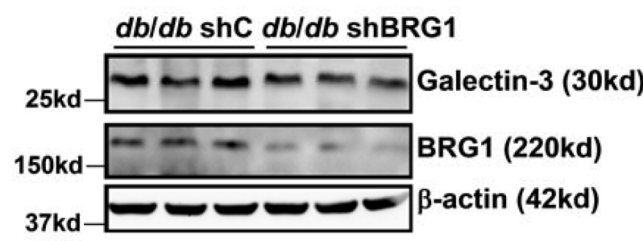

FIGURE 1 | BRG1 regulates injury induced galectin-3 up-regulation in the liver. (A,B) WT and CKO mice were given weekly injection of corn oil or CCl 4 for 6 weeks. Hepatic expression of galectin-3 was examined by qPCR and Western. (C,D) WT and CKO mice were injected with saline or APAP (300 mg/kg) and sacrificed $48 \mathrm{~h}$ after the injection. Hepatic expression of galectin-3 was examined by qPCR and Western. (E,F) WT and CKO mice were fed an MCD diet or a control diet for 8 weeks. Hepatic expression of galectin-3 was examined by qPCR and Western. (G,H) WT and CKO mice were fed an HFD diet or a control diet for 8 weeks. Hepatic expression of galectin-3 was examined by qPCR and Western. (I,J) Db/db mice and db/ + mice were injected with lentivirus carrying shRNA targeting BRG1 or a control shRNA. Hepatic expression of galectin-3 was examined by qPCR and Western. Error bars represent SD $\left({ }^{*} p<0.05\right.$, one-way ANOVA with post hoc Scheffe test). 
A

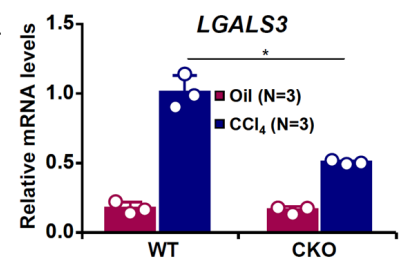

C

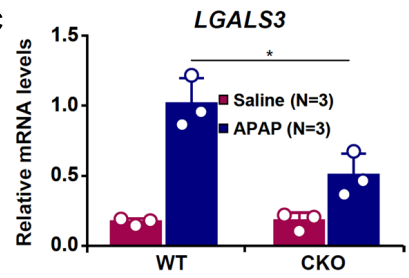

B
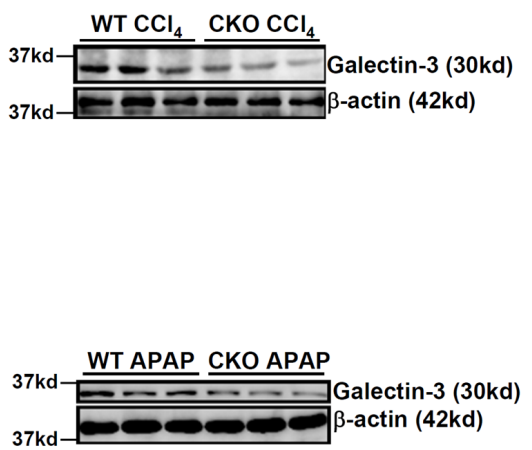

E

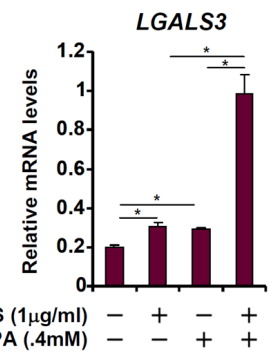

F

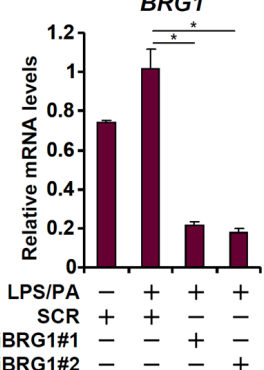

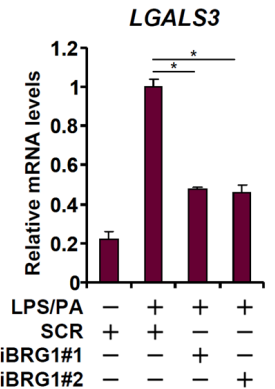

G

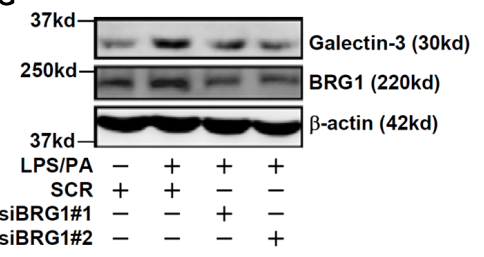

H

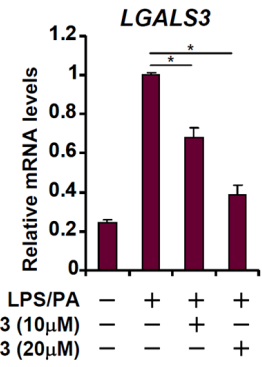

I

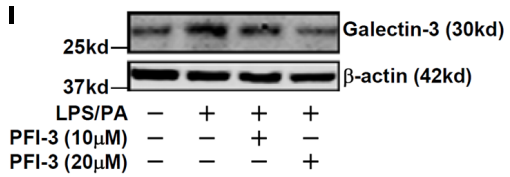

J

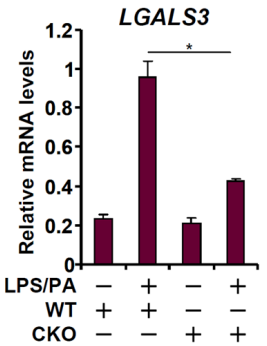

K

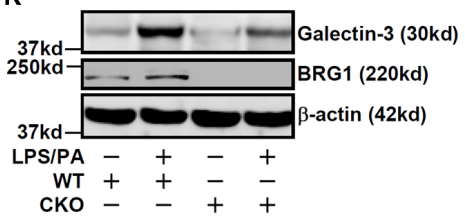

FIGURE 2 | BRG1 regulates galectin-3 up-regulation in cultured hepatocytes. (A,B) WT and CKO mice were given weekly injection of corn oil or CCl 4 for 6 weeks. Primary hepatocytes were isolated and expression of galectin-3 was examined by qPCR and Western. (C,D) WT and CKO mice were injected with saline or APAP (300 mg/kg) and sacrificed $48 \mathrm{~h}$ after the injection. Primary hepatocytes were isolated and expression of galectin-3 was examined by qPCR and Western. (E) HepG2 cells were treated with LPS and/or palmitate for 24 hours. Galectin-3 expression was examined by qPCR. (F,G) HepG2 cells were transfected with small interfering RNA targeting BRG1 or scrambled siRNA (SCR) followed by treatment with LPS plus palmitate. Galectin-3 expression was examined by qPCR and Western. (H,I) HepG2 cells were treated with LPS plus palmitate in the presence or absence of PFI-3. Galectin-3 expression was examined by qPCR and Western. (J,K) Primary hepatocytes were isolated from WT and CKO mice and treated with or without LPS plus palmitate. Galectin-3 expression was examined by qPCR and Western. Data represent averages of three independent experiments. Data represent averages of three independent experiments and error bars represent $\mathrm{SEM}\left({ }^{*} p<0.05\right.$, one-way ANOVA with post hoc Scheffe test). 
Visentin et al., 2018). Therefore, we sought to determine whether BRG1 deficiency in hepatocytes would similarly regulate galectin3 expression in response to LPS and free fatty acids. As shown in Figure 2E, treatment with LPS $(1 \mu \mathrm{g} / \mathrm{ml})$ or palmitate $(0.4 \mathrm{mM})$ led to a small but significant up-regulation of galectin3 expression in HepG2 cells; combined treatment of LPS and palmitate, however, evoked a much stronger induction of galectin-3 expression. Therefore, LPS plus palmitate was used to stimulate galectin-3 expression in cultured cells hereafter. Depletion of BRG1 with siRNAs markedly suppressed induction of galectin-3 expression by LPS plus palmitate (Figures 2F,G). Likewise, inhibition of BRG1 activity with a small-molecule compound (PFI-3) dose-dependently reversed induction of galectin-3 expression by LPS plus palmitate (Figures 2H,I). Finally, when primary hepatocytes were isolated from both WT and CKO mice and treated with LPS plus palmitate, the induction of galectin-3 expression was much stronger in WT cells than in CKO cells (Figures 2J,K). Of note, galectin-3 expression was still inducible, even though not quite as strong as WT cells, in BRG1 CKO cells by LPS plus palmitate indicative of a BRG1independent mechanism.

\section{BRG1 Directly Binds to the Galectin-3 Promoter to Activate Transcription}

We next investigated how BRG1 could be recruited to the galectin-3 promoter in response to injurious stimuli. A series of galectin-3 promoter-luciferase constructs with progressively inward deletions were transfected into HepG2 cells. Overexpression of BRG1 in the presence of LPS plus palmitate markedly augmented the galectin-3 promoter activity until the deletion extended beyond a region containing an AP-1 binding site (Figure 3A). Indeed, mutation of this AP-1 site abrogated the induction of galectin- 3 promoter activity by BRG1 over-expression (Figure 3B). ChIP assays showed that when the cells were exposed to the injurious stimuli, both AP-1 and BRG1 were recruited to the same region of the galectin-3 promoter with comparable kinetics; depletion of AP-1 with siRNAs significantly diminished BRG1 binding to the galectin-3 promoter (Figures 3C,D). Co-immunoprecipitation assay confirmed that BRG1 interacted with AP-1 in HepG2 cells (Figure 3E). More important, Re-ChIP assay detected the presence of a BRG1-AP-1 complex on the galectin-3 promoter only when the cells were stimulated with LPS plus palmitate (Figure 3F). Together, these data suggest that BRG1 may rely on AP-1 to activate galectin-3 transcription.

\section{BRG1 Regulates DNA Demethylation on the Galectin-3 Promoter}

We next determined the epigenetic mechanism whereby BRG1 may contribute to galectin-3 transcription. ChIP assays revealed that in response to treatment with LPS plus palmitate, levels of acetylated histone $\mathrm{H} 3(\mathrm{AcH} 3$, Figure 4A) and trimethylated $\mathrm{H} 3 \mathrm{~K} 4$ (H3K4Me3, Figure 4B), both of which are well-established markers for active transcription, were slightly up-regulated on the galectin-3 promoter; BRG1 knockdown marginally influenced AcH3 and H3K4Me3 levels.
On the contrary, levels of dimethylated H3K9 (H3K9Me2, Figure 4C), known to mark repressed chromatin, were significantly down-regulated on the galectin-3 promoter upon the addition of LPS plus palmitate; BRG1 depletion abolished the erasure of H3K9Me2 from the galectin-3 promoter. Further, there was a simultaneous disappearance of 5-methylcytosine (Figure 4D) and acquisition of 5hydroxymethylcytosine (Figure 4E) on the galectin-3 promoter paralleling its trans-activation, a trend that was reversed by the loss of BRG1.

We performed similar experiments using primary hepatocytes isolated from WT and $\mathrm{CKO}$ mice. AcH3 (Figure 4F) and H3K4Me3 (Figure 4G) levels were minimally altered by the treatment of LPS plus palmitate with or without BRG1. In sharp contrast, BRG1 deficiency was associated with the re-appearance of $\mathrm{H} 3 \mathrm{~K} 9 \mathrm{Me} 2$ (Figure $4 \mathbf{H}$ ) and 5-methylcytosine (Figure 4I) as well as the suppression of 5-hydroxymethylcytosine (Figure 4J). Combined, these data suggest that BRG1-dependent removal of repressive epigenetic traits on the galectin-3 promoter may be the rate-limiting step for its trans-activation.

\section{BRG1 Cooperates With TET1 to Activate Galectin-3 Transcription}

Because BRG1 appeared to be essential for DNA (cytosine) demethylation on the galectin-3 promoter we naturally hypothesized that it may interact and recruit the TET family of dioxygenases to the galectin-3 promoter. As shown in Figure 5A, TET1, but not TET2 or TET3, occupied the galectin-3 promoter with significant affinity when HepG2 cells were treated with LPS plus palmitate; BRG1 knockdown dampened TET1 binding without altering the binding patterns of either TET2 or TET3. Similarly, LPS plus palmitate treatment promoted TET1 recruitment to the galectin-3 promoter in primary hepatocytes isolated from WT mice but not from CKO mice (Figure 5B), confirming the essential role of BRG1 in recruiting TET1. Co-immunoprecipitation experiments provided additional evidence that there was an interaction between BRG1 and TET1 in hepatocytes (Figure 5C). ReChIP assays confirmed that a BRG1-TET1 complex was clearly detectable on the galectin-3 promoter following the stimulation with LPS plus palmitate (Figure 5D). Finally, we asked whether TET1 might be essential for galectin-3 induction. Knockdown of TET1 with two different siRNAs comparably suppressed the induction of both mRNA (Figure 5E) and protein (Figure 5F) levels of galectin-3 by LPS plus palmitate. We therefore conclude that injurious stimuli induced galectin-3 expression in hepatocytes may be attributable to an interplay between BRG1 and TET1.

\section{DISCUSSION}

Galectin-3 levels are sensitive to the disruption of cellular homeostasis (Mishra et al., 2013; Venkatraman et al., 2018). Here we detail a novel epigenetic pathway wherein the chromatin remodeling protein BRG1 contributes to galectin-3 induction by injurious stimuli in hepatocytes by the DNA demethylase 
A

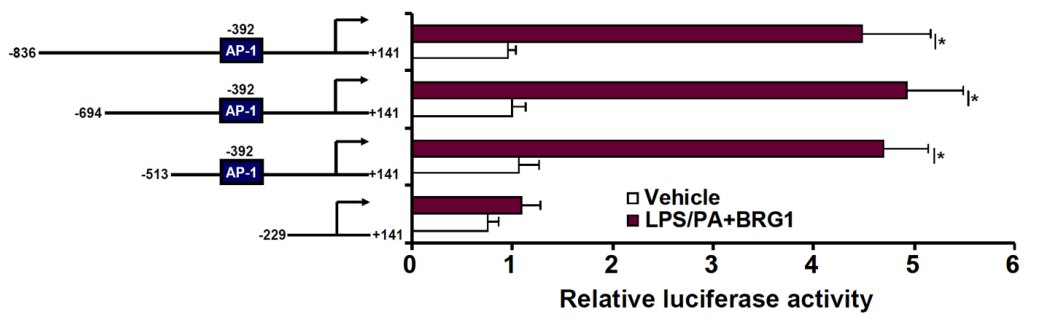

B
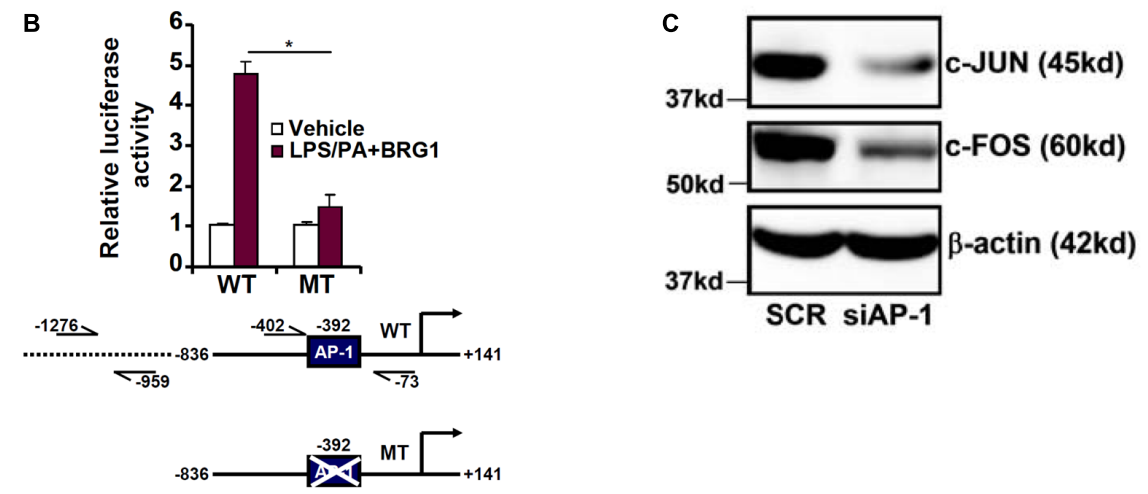

SCR SIAP-1

D
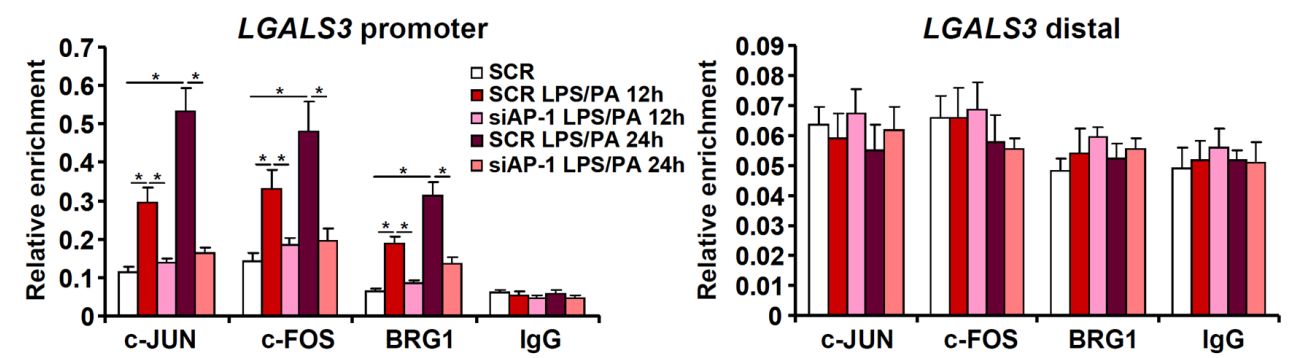

$\mathbf{E}$

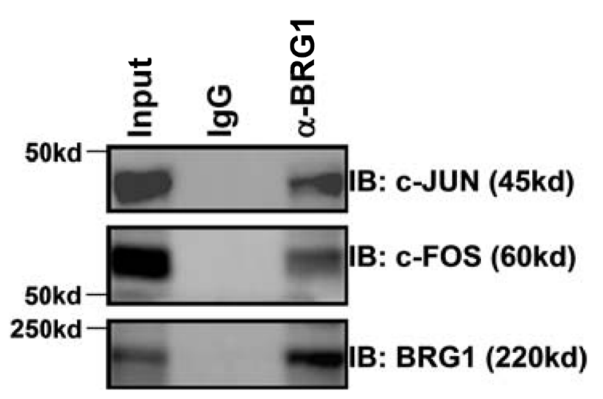

$\mathbf{F}$

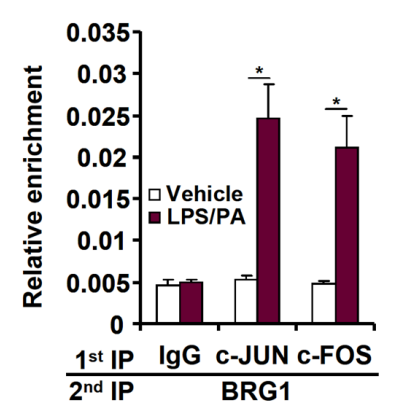

LGALS3 distal

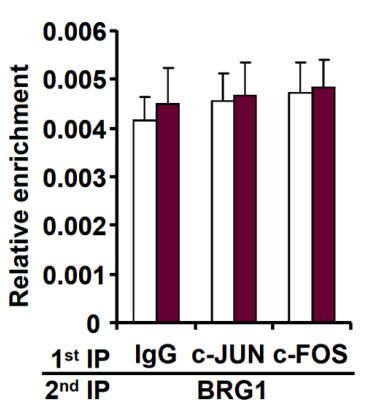

FIGURE 3 | BRG1 interacts with AP-1 to activate galectin-3 transcription in hepatocytes. (A) Galectin-3 promoter-luciferase constructs of varying lengths were transfected into HepG2 cells with or without BRG1 followed by treatment with LPS plus palmitate. Luciferase activities were normalized to both GFP fluorescence and protein concentration. (B) Wild type or AP-1 site mutated galectin-3 promoter-luciferase construct was transfected into HepG2 cells with or without BRG1 followed by treatment with LPS plus palmitate. Luciferase activities were normalized to both GFP fluorescence and protein concentration. (C,D) HepG2 cells were transfected with siRNA targeting AP-1 or SCR followed by treatment with LPS plus palmitate. ChIP assays were performed with indicated antibodies. (E) HepG2 cells were treated with LPS plus palmitate. Nuclear proteins were extracted and immunoprecipitated with indicated antibodies. (F) HepG2 cells were treated with or without LPS plus palmitate. Re-ChIP assays were performed with indicated antibodies. Data represent averages of three independent experiments and error bars represent SEM $(* p<0.05$, one-way ANOVA with post hoc Scheffe test). 


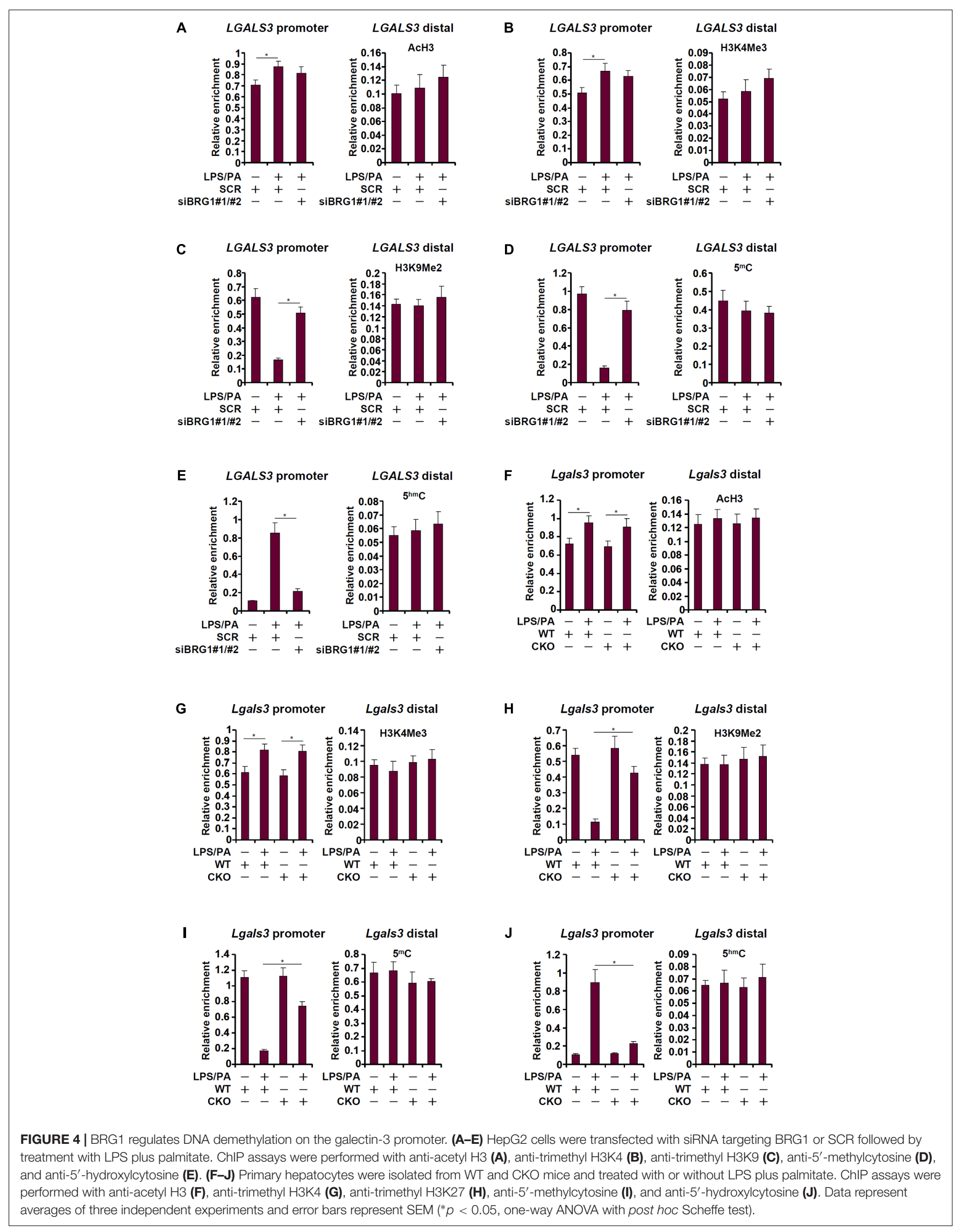


A

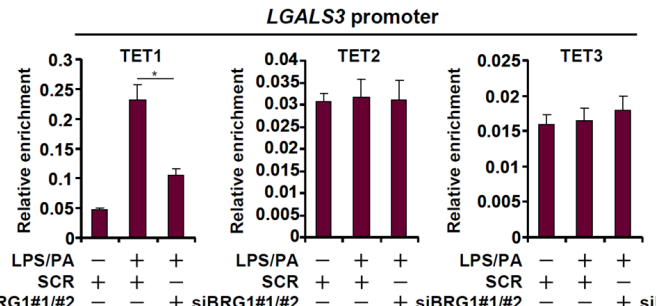

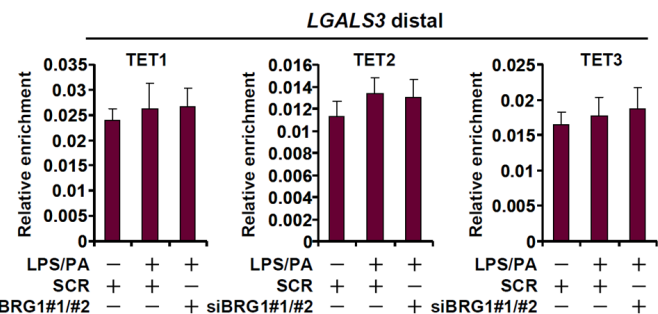

Lgals3 distal

B
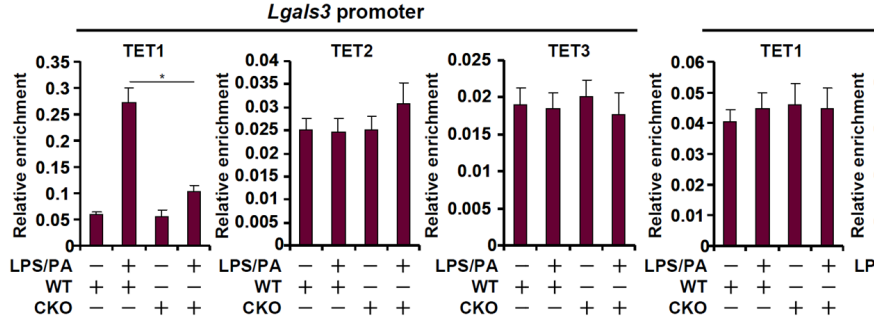

C

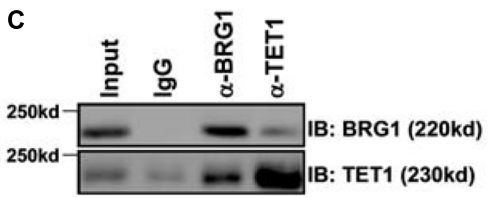

D LGALS3 promoter LGALS3 distal
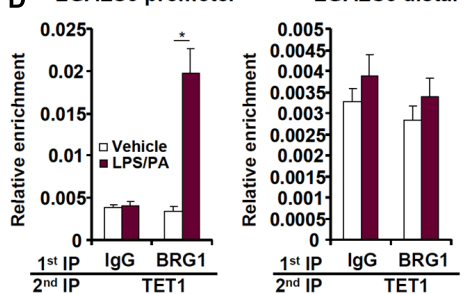

$\mathbf{E}$

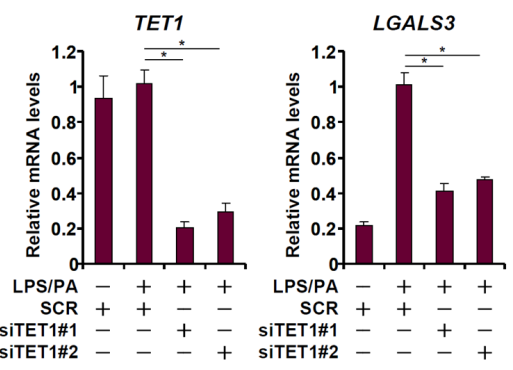

$\mathbf{F}$

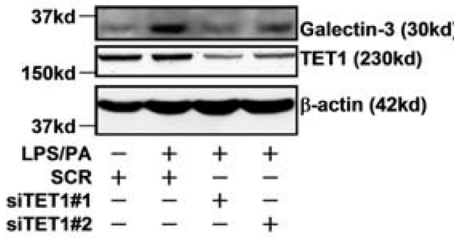

G

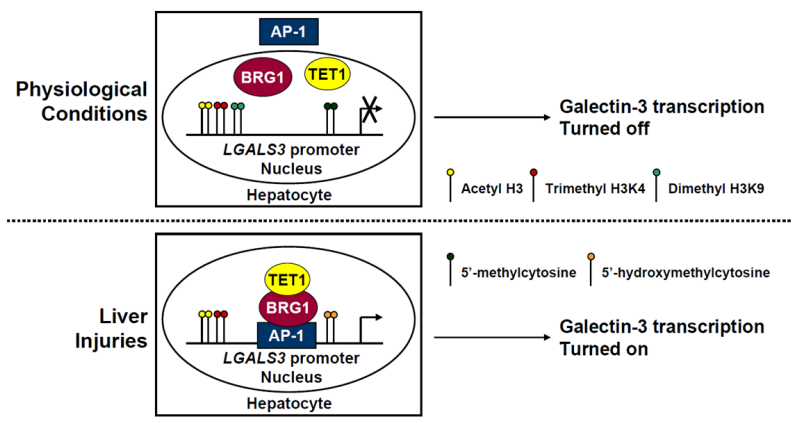

FIGURE 5 | BRG1 cooperates with TET1 to activate galectin-3 transcription. (A) HepG2 cells were transfected with siRNA targeting BRG1 or SCR followed by treatment with LPS plus palmitate. ChIP assays were performed with indicated antibodies. (B) Primary hepatocytes were isolated from WT and CKO mice and treated with or without LPS plus palmitate. ChIP assays were performed with indicated antibodies. (C) HepG2 cells were treated with LPS plus palmitate. Nuclear proteins were extracted and immunoprecipitated with indicated antibodies. (D) HepG2 cells were treated with or without LPS plus palmitate. Re-ChIP assays were performed with indicated antibodies. (E,F) HepG2 cells were transfected with siRNA targeting TET1 or SCR followed by treatment with LPS plus palmitate. Galectin-3 expression was examined by GPCR and Western. Data represent averages of three independent experiments. Data represent averages of three independent experiments and error bars represent SEM ( ${ }^{p} p<0.05$, one-way ANOVA with post hoc Scheffe test). (G) A schematic model. 
(dioxygenase) TET1 (Figure 5G). Of interest, fairly high levels of acetyl histone $\mathrm{H} 3$ and trimethyl $\mathrm{H} 3 \mathrm{~K} 4$ were present on the galectin-3 promoter under basal conditions, which were slightly augmented upon stimulation with injurious treatment and marginally decreased by BRG1 silencing (Figure 4). Instead, BRG1 regulated galectin-3 transcription primarily by facilitating the removal of repressive modifications including dimethyl H3K9 and 5'-methylcytosine from the galectin-3 promoter. This observation contrasts previous findings where BRG1 has been shown to regulate transcription by helping recruit histone acetyltransferases and H3K4 methyltransferases (Fang et al., 2013; Li et al., 2018a,b; Zhang et al., 2018). On the other hand, Sepulveda et al. $(2017 \mathrm{a}, \mathrm{b})$ have reported that BRG1 may regulate osteoblast differentiation by contributing to the activation of genes with bivalent promoters. In fact, genome-wide profiling of BRG1 target genes in eight cell lines derived from malignant rhabdoid tumors demonstrates that fewer than $10 \%$ are bivalent (Nakayama et al., 2017). These data combined allude to the versatility of BRG1 in terms of promoter selection.

There are several lingering issues that need to be addressed in future investigations. First, although our data indicate that activation of galectin-3 transcription was also accompanied by erasure of dimethyl $\mathrm{H} 3 \mathrm{~K} 9$, in addition of DNA demethylation, in a BRG1-dependent manner, the identity of the responsible $\mathrm{H} 3 \mathrm{~K} 9$ demethylase remains to be investigated. We have previously shown that BRG1 interacts with the H3K9 demethylase KDM3A to activate colony stimulating factor (CSF1) transcription in endothelial cells (Zhang et al., 2018; Shao et al., 2019). KDM3A has been proposed as a stress response factor in a number of diseased states. For instance, KDM3A can sense low oxygen tension (hypoxia) in hepatocytes to regulate cell proliferation, migration, and invasion (Beyer et al., 2008; Yamada et al., 2012; Park et al., 2013). It would be of great interest to determine whether KDM3A may contribute to galectin-3 transcription in hepatocytes and, by extension, liver injury. Second, how BRG1 itself is regulated by divergent injurious stimuli to activate transcription was not examined in the present study. Several different factors may collectively contribute to signal-dependent activation of BRG1. BRG1 is predominantly nucleus-bound so its recruitment to target promoters largely depends on the availability of sequence-specific transcription factors. We show here that AP-1, the nuclear translocation of which can be stimulated by LPS and palmitate (Guha et al., 2001; Cazanave et al., 2010), interacted with BRG1 and recruited BRG1 to the galectin-3 promoter. It was also noted that expression levels of BRG1 was slightly but significantly up-regulated by injurious stimuli (Figures 2C,G) that may account for the overall augmented BRG1 activity although it is unclear whether this change was solely the result of increased transcription rate or enhanced protein stability or a combination of both. The human SMARCA4 promoter encoding BRG1 has yet to be functionally characterized. Coira et al. (2015) have recently reported that a group of miRNAs can target the $3^{\prime}$ untranslated region of the SMARCA4 mRNA to down-regulate BRG1 expression in human lung cancer cells. In addition, specific ubiquitin ligases have been also been identified for BRG1 (Sohn et al., 2007;
Huang et al., 2018). Clearly further investigations are warranted to clarify whether these mechanisms may contribute to signalinduced activation of BRG1. Finally, although we focused our investigation on the regulation of galectin-3 transcription in hepatocytes it should be pointed out that galectin-3 expression has been detected in other liver cell types. For instance, Henderson et al. have observed that galectin-3 expression is significantly up-regulated in hepatic stellate cells (HSCs) as they transition from a quiescent phenotype to an activated phenotype (Henderson et al., 2006). Dragomir et al. have reported that galectin-3 expression in macrophages can be induced by APAP in mice, which is associated with a pro-inflammatory phenotype switch of macrophages (Dragomir et al., 2012a). More recently, it has been suggested that galectin-3 expression in down-regulated in $\mathrm{CD} 68+$ macrophages but up-regulated in a-SMA ${ }^{+}$cells in the liver in children diagnosed with steatosis (de Oliveira et al., 2019). Therefore, although hepatocytes constitute the bulk of the liver mass, other cell populations, including Kupffer cells, cuboidal epithelial cells, fibroblasts, sinusoidal endothelial cells, intrahepatic lymphocytes, and HSCs, may produce galectin-3 molecules that contribute to the overall pool of galectin-3 in the liver. It remains to be tested whether the model as proposed here may be applied to other cell types in the liver exposed to injurious stimuli.

We provide evidence to implicate an interaction between BRG1 and the DNA dioxygenase TET1 in the induction of galectin-3 expression. Fazzio and colleagues have previously shown that BRG1 and TET1 can be purified from the same mega-protein complex in embryonic stem cells (ESCs) (Yildirim et al., 2011). Coincidentally, BRG1 and TET1 are shown to coregulate a subset of bivalent promoters in ESCs. Of interest, TET1 depletion appears to influence the recruitment of BRG1 to target promoters suggestive of an inter-dependence between BRG1 and TET1 in regulating gene transcription (Yildirim et al., 2011). Curiously, both TET2 (Sepulveda et al., 2017b) and TET3 (Lan et al., 2019) have been reported to cooperate with BRG1 to regulate transcription raising the intriguing question as to how BRG1 selectively interacts with different TETs to regulate transcription. One possible explanation is the availability of different TETs in a given cell type because TET proteins clearly exhibit show distinct expression patterns (Tan and Shi, 2012). For instance, TET1 is the predominant TET isoform detected in HepG2 cells (Chuang et al., 2015). Alternatively, the interaction between BRG1 and different TETs may be fine-tuned by structural components of the SWI/SNF complex (Long et al., 2013; Chandru et al., 2018). Clear delineation of the dynamic interaction between BRG1 and TET proteins, which clearly goes beyond the scope of the present study, is of tremendous help to better appreciation of the underpinnings of transcriptional regulation by the epigenetic machinery.

In summary, our data unveil a novel epigenetic pathway that contributes to galectin-3 trans-activation during liver injury. Further studies using animal models will not only validate the current working model (Figure 5G) but provide further rationale for using this BRG1-TET1 complex as a druggable target for the intervention of liver injuries. 


\section{DATA AVAILABILITY STATEMENT}

The raw data supporting the conclusions of this manuscript will be made available by the authors, without undue reservation, to any qualified researcher.

\section{ETHICS STATEMENT}

The animal study was reviewed and approved by the Nanjing Medical University Ethics Committee on Humane Treatment of Experimental Animals.

\section{AUTHOR CONTRIBUTIONS}

YX and MF conceived the project. ZL, FL, MF, CJ, and YX designed the experiments. ZL, FL, QW, CJ, and MF performed

\section{REFERENCES}

Begriche, K., Massart, J., Robin, M. A., Borgne-Sanchez, A., and Fromenty, B. (2011). Drug-induced toxicity on mitochondria and lipid metabolism: mechanistic diversity and deleterious consequences for the liver. J. Hepatol. 54, 773-794. doi: 10.1016/j.jhep.2010.11.006

Beyer, S., Kristensen, M. M., Jensen, K. S., Johansen, J. V., and Staller, P. (2008). The histone demethylases JMJD1A and JMJD2B are transcriptional targets of hypoxia-inducible factor HIF. J. Biol. Chem. 283, 36542-36552. doi: 10.1074/ jbc.M804578200

Bultman, S., Gebuhr, T., Yee, D., La Mantia, C., Nicholson, J., Gilliam, A., et al. (2000). A Brg1 null mutation in the mouse reveals functional differences among mammalian SWI/SNF complexes. Mol. Cell. 6, 1287-1295 doi: 10.1016/s10972765(00)00127-1

Bultman, S. J., Gebuhr, T. C., and Magnuson, T. (2005). A Brg1 mutation that uncouples ATPase activity from chromatin remodeling reveals an essential role for SWI/SNF-related complexes in beta-globin expression and erythroid development. Genes Dev. 19, 2849-2861. doi: 10.1101/gad.136 4105

Cazanave, S. C., Elmi, N. A., Akazawa, Y., Bronk, S. F., Mott, J. L., and Gores, G. J. (2010). CHOP and AP-1 cooperatively mediate PUMA expression during lipoapoptosis. Am. J. Physiol. Gastrointest. Liver Physiol. 299, G236-G243. doi: 10.1152/ajpgi.00091.2010

Chaiyachati, B. H., Jani, A., Wan, Y., Huang, H., Flavell, R., and Chi, T. (2013). BRG1-mediated immune tolerance: facilitation of Treg activation and partial independence of chromatin remodelling. EMBO J. 32, 395-408. doi: 10.1038/ emboj.2012.350

Chandru, A., Bate, N., Vuister, G. W., and Cowley, S. M. (2018). Sin3A recruits Tet1 to the PAH1 domain via a highly conserved Sin3-interaction domain. Sci. Rep. 8:14689. doi: 10.1038/s41598-018-32942-w

Chen, D., Fang, F., Yang, Y., Chen, J., Xu, G., Xu, Y., et al. (2013). Brahmarelated gene 1 ( $\mathrm{Brg} 1$ ) epigenetically regulates CAM activation during hypoxic pulmonary hypertension. Cardiovasc. Res. 100, 363-373. doi: 10.1093/cvr/ cvt214

Chen, Z., Liu, Y., Yao, L., Guo, S., Gao, Y., and Zhu, P. (2018). The long noncoding RNA lncZic2 drives the self-renewal of liver tumor-initiating cells via the protein kinase C substrates MARCKS and MARCKSL1. J. Biol. Chem. 293, 7982-7992. doi: 10.1074/jbc.RA117.001321

Chiariotti, L., Salvatore, P., Frunzio, R., and Bruni, C. B. (2002). Galectin genes: regulation of expression. Glycoconj. J. 19, 441-449. doi: 10.1023/B:GLYC. 0000014073.23096.3a

Chuang, K. H., Whitney-Miller, C. L., Chu, C. Y., Zhou, Z., Dokus, M. K., Schmit, S., et al. (2015). MicroRNA-494 is a master epigenetic regulator of multiple invasion-suppressor microRNAs by targeting ten eleven translocation 1 in the experiments, collected the data, and analyzed the data. CJ, CD, and MF provided funding and supervised the project. YX wrote the manuscript with inputs from all authors.

\section{FUNDING}

This work was supported in part by grants from the National Natural Science Foundation of China (81570420 and 81870302) and Chinese Medicine Science and Technology Development Plan of Jiangsu Province (YB201916).

\section{SUPPLEMENTARY MATERIAL}

The Supplementary Material for this article can be found online at: https://www.frontiersin.org/articles/10.3389/fcell.2019.00310/ full\#supplementary-material

invasive human hepatocellular carcinoma tumors. Hepatology 62, 466-480. doi: $10.1002 /$ hep. 27816

Coira, I. F., Rufino-Palomares, E. E., Romero, O. A., Peinado, P., Metheetrairut, C., Boyero-Corral, L., et al. (2015). Expression inactivation of SMARCA4 by microRNAs in lung tumors. Hum. Mol. Genet. 24, 1400-1409. doi: 10.1093/ hmg/ddu554

de Oliveira, F. L., Panera, N., De Stefanis, C., Mosca, A., D’Oria, V., Crudele, A., et al. (2019). The Number of liver galectin-3 positive cells is dually correlated with NAFLD severity in children. Int. J. Mol. Sci. 20:E3460. doi: 10.3390/ ijms20143460

Dragomir, A. C., Sun, R., Choi, H., Laskin, J. D., and Laskin, D. L. (2012a). Role of galectin-3 in classical and alternative macrophage activation in the liver following acetaminophen intoxication. J. Immunol. 189, 5934-5941. doi: 10.4049/jimmunol.1201851

Dragomir, A. C., Sun, R., Mishin, V., Hall, L. B., Laskin, J. D., and Laskin, D. L. (2012b). Role of galectin-3 in acetaminophen-induced hepatotoxicity and inflammatory mediator production. Toxicol. Sci. 127, 609-619. doi: 10.1093/ toxsci/kfs117

Eroglu, B., Wang, G., Tu, N., Sun, X., and Mivechi, N. F. (2006). Critical role of Brg1 member of the SWI/SNF chromatin remodeling complex during neurogenesis and neural crest induction in zebrafish. Dev. Dyn. 235, 2722-2735. doi: 10.1002/ dvdy. 20911

Fan, Z., Li, N., Xu, Z., Wu, J., Fan, X., and Xu, Y. (2019). An interaction between MKL1, BRG1, and C/EBPbeta mediates palmitate induced CRP transcription in hepatocytes. Biochim. Biophys. Acta Gene. Regul. Mech. 1862:194412. doi: 10.1016/j.bbagrm.2019.194412

Fan, Z., Li, Z., Yang, Y., Liu, S., Guo, J., and Xu, Y. (2017). HIF-1alpha coordinates epigenetic activation of SIAH1 in hepatocytes in response to nutritional stress. Biochim. Biophys. Acta Gene. Regul. Mech. 1860, 1037-1046. doi: 10.1016/j. bbagrm.2017.08.002

Fang, F., Chen, D., Yu, L., Dai, X., Yang, Y., Tian, W., et al. (2013). Proinflammatory stimuli engage Brahma related gene 1 and Brahma in endothelial injury. Circ. Res. 113, 986-996. doi: 10.1161/CIRCRESAHA.113.30 1296

Griffin, C. T., Brennan, J., and Magnuson, T. (2008). The chromatin-remodeling enzyme BRG1 plays an essential role in primitive erythropoiesis and vascular development. Development 135, 493-500. doi: 10.1242/dev.010090

Griffin, C. T., Curtis, C. D., Davis, R. B., Muthukumar, V., and Magnuson, T. (2011). The chromatin-remodeling enzyme BRG1 modulates vascular Wnt signaling at two levels. Proc. Natl. Acad. Sci. U.S.A. 108, 2282-2287. doi: 10. 1073/pnas.1013751108

Guha, M., O’Connell, M. A., Pawlinski, R., Hollis, A., McGovern, P., Yan, S. F., et al. (2001). Lipopolysaccharide activation of the MEK-ERK1/2 pathway in human monocytic cells mediates tissue factor and tumor necrosis factor alpha 
expression by inducing Elk-1 phosphorylation and Egr-1 expression. Blood 98, 1429-1439. doi: 10.1182/blood.v98.5.1429

Hang, C. T., Yang, J., Han, P., Cheng, H. L., Shang, C., Ashley, E., et al. (2010). Chromatin regulation by $\mathrm{Brg} 1$ underlies heart muscle development and disease. Nature 466, 62-67. doi: 10.1038/nature09130

Harikumar, A., and Meshorer, E. (2015). Chromatin remodeling and bivalent histone modifications in embryonic stem cells. EMBO Rep. 16, 1609-1619. doi: 10.15252/embr.201541011

Henderson, N. C., Mackinnon, A. C., Farnworth, S. L., Poirier, F., Russo, F. P., Iredale, J. P., et al. (2006). Galectin-3 regulates myofibroblast activation and hepatic fibrosis. Proc. Natl. Acad. Sci. U.S.A. 103, 5060-5065. doi: 10.1073/pnas. 0511167103

Huang, L. Y., Zhao, J., Chen, H., Wan, L., Inuzuka, H., Guo, J., et al. (2018). SCF(FBW7)-mediated degradation of Brgl suppresses gastric cancer metastasis. Nat. Commun. 9:3569. doi: 10.1038/s41467-018-06038-y

Huang, M., Wang, H., Hu, X., and Cao, X. (2019). IncRNA MALAT1 binds chromatin remodeling subunit BRG1 to epigenetically promote inflammationrelated hepatocellular carcinoma progression. Oncoimmunology 8:e1518628. doi: 10.1080/2162402X.2018.1518628

Jeftic, I., Jovicic, N., Pantic, J., Arsenijevic, N., Lukic, M.L., and Pejnovic, N. (2015). Galectin-3 Ablation Enhances Liver Steatosis, but Attenuates Inflammation and IL-33-Dependent Fibrosis in Obesogenic Mouse Model of Nonalcoholic Steatohepatitis. Mol. Med. 21, 453-465. doi: 10.2119/molmed. 2014.00178

Kadrofske, M. M., Openo, K. P., and Wang, J. L. (1998). The human LGALS3 (galectin-3) gene: determination of the gene structure and functional characterization of the promoter. Arch. Biochem. Biophys. 349, 7-20. doi: 10. 1006/abbi.1997.0447

Kong, M., Chen, X., Lv, F., Ren, H., Fan, Z., Qin, H., et al. (2019a). Serum response factor (SRF) promotes ROS generation and hepatic stellate cell activation by epigenetically stimulating NCF1/2 transcription. Redox Biol. 26:101302. doi: 10.1016/j.redox.2019.101302

Kong, M., Chen, X., Xu, H., Wenping, Fang, M., and Xu, Y. (2018). Hepatocytespecific deletion of $\mathrm{Brg} 1$ alleviates methionine-and-choline-deficient diet (MCD) induced non-alcoholic steatohepatitis in mice. Biochem. Biophys. Res. Commun. 503, 344-351. doi: 10.1016/j.bbrc.2018.06.027

Kong, M., Hong, W., Shao, Y., Lv, F., Fan, Z., Li, P., et al. (2019b). Ablation of serum response factor in hepatic stellate cells attenuates liver fibrosis. J. Mol. Med. [Epub ahead of print].

Lan, Y., Pan, H., Li, C., Banks, K. M., Sam, J., Ding, B., et al. (2019). TETs Regulate Proepicardial Cell Migration through Extracellular Matrix Organization during Zebrafish Cardiogenesis. Cell Rep. 26:720-732.e4. doi: 10.1016/j.celrep.2018. 12.076

Ledford, H. (2015). Epigenetics: the genome unwrapped. Nature 528, S12-S13. doi: $10.1038 / 528 S 12 a$

Leisegang, M. S., Fork, C., Josipovic, I., Richter, F. M., Preussner, J., Hu, J., et al. (2017). Long noncoding RNA MANTIS facilitates endothelial angiogenic function. Circulation 136, 65-79. doi: 10.1161/CIRCULATIONAHA.116. 026991

Lennartsson, A., and Ekwall, K. (2009). Histone modification patterns and epigenetic codes. Biochim. Biophys. Acta 1790, 863-868. doi: 10.1016/j.bbagen. 2008.12 .006

Li, M., Hong, W., Hao, C., Li, L., Xu, H., Li, P., et al. (2017). Hepatic stellate cellspecific deletion of SIRT1 exacerbates liver fibrosis in mice. Biochim. Biophys. Acta 1863, 3202-3211. doi: 10.1016/j.bbadis.2017.09.008

Li, N., Kong, M., Zeng, S., Hao, C., Li, M., Li, L., et al. (2019a). Brahma related gene $1(\mathrm{Brg} 1)$ contributes to liver regeneration by epigenetically activating the Wnt/beta-catenin pathway in mice. FASEB J. 33, 327-338. doi: 10.1096/fj. 201800197R

Li, N., Kong, M., Zeng, S., Xu, Z., Li, M., Hong, W., et al. (2018a). The chromatin remodeling protein BRG1 regulates APAP-induced liver injury by modulating CYP3A11 transcription in hepatocyte. Biochim. Biophys. Acta Mol. Basis Dis. 1864, 3487-3495. doi: 10.1016/j.bbadis.2018.08.003

Li, N., Li, M., Hong, W., Shao, J., Xu, H., Shimano, H., et al. (2018b). Brg1 regulates pro-lipogenic transcription by modulating SREBP activity in hepatocytes. Biochim. Biophys. Acta Mol. Basis Dis. 1864(9 Pt B), 2881-2889. doi: 10.1016/ j.bbadis.2018.05.022
Li, Z., Chen, B., Dong, W., Xu, W., Song, M., Fang, M., et al. (2018c). Epigenetic activation of PERP transcription by MKL1 contributes to ROS-induced apoptosis in skeletal muscle cells. Biochim. Biophys. Acta Gene. Regul. Mech. 1861, 905-915. doi: 10.1016/j.bbagrm.2018.07.011

Li, Z., Chen, B., Weng, X., Yu, L., Song, M., Fang, M., et al. (2018d). The histone methyltransferase SETD1A regulates thrombomodulin transcription in vascular endothelial cells. Biochim. Biophys. Acta Gene. Regul Mech. 1861, 752-761. doi: 10.1016/j.bbagrm.2018.06.004

Li, Z., Li, P., Lu, Y., Sun, D., Zhang, X., and Xu, Y. (2019b). A non-autonomous role of MKL1 in the activation of hepatic stellate cells. Biochim. Biophys. Acta Gene. Regul. Mech. 1862, 609-618. doi: 10.1016/j.bbagrm.2019.03.001

Li, Z., Zhang, X., Liu, S., Zeng, S., Yu, L., Yang, G., et al. (2018e). BRG1 regulates NOX gene transcription in endothelial cells and contributes to cardiac ischemia-reperfusion injury. Biochim. Biophys. Acta Mol. Basis Dis. 1864, $3477-$ 3486. doi: 10.1016/j.bbadis.2018.08.002

Liu, L., Hong, W., Li, M., Ren, H., Wang, J., Xu, H., et al. (2019a). A Cross Talk Between BRG1 and Males Absent on the First Contributes to Reactive Oxygen Species Production in a Mouse Model of Nonalcoholic Steatohepatitis. Antioxid. Redox. Signal. 30, 1539-1552. doi: 10.1089/ars.2016.6822

Liu, L., Mao, L., Wu, X., Wu, T., Liu, W., Yang, Y., et al. (2019b). BRG1 regulates endothelial-derived IL-33 to promote ischemia-reperfusion induced renal injury and fibrosis in mice. Biochim. Biophys. Acta Mol. Basis Dis. 1865, 2551-2561. doi: 10.1016/j.bbadis.2019.06.015

Liu, L., Wu, X., Xu, H., Yu, L., Zhang, X., Li, L., et al. (2018). Myocardinrelated transcription factor A (MRTF-A) contributes to acute kidney injury by regulating macrophage ROS production. Biochim. Biophys. Acta Mol. Basis Dis. 1864, 3109-3121. doi: 10.1016/j.bbadis.2018.05.026

Locatelli, I., Sutti, S., Jindal, A., Vacchiano, M., Bozzola, C., Reutelingsperger, C., et al. (2014). Endogenous annexin Al is a novel protective determinant in nonalcoholic steatohepatitis in mice. Hepatology 60, 531-544. doi: 10.1002/hep. 27141

Long, H. K., Blackledge, N. P., and Klose, R. J. (2013). ZF-CxxC domain-containing proteins, CpG islands and the chromatin connection. Biochem. Soc. Trans. 41, 727-740. doi: 10.1042/BST20130028

Mishra, B. B., Li, Q., Steichen, A. L., Binstock, B. J., Metzger, D. W., Teale, J. M., et al. (2013). Galectin-3 functions as an alarmin: pathogenic role for sepsis development in murine respiratory tularemia. PLoS One 8:e59616. doi: 10.1371/ journal.pone. 0059616

Naidu, S. R., Love, I. M., Imbalzano, A. N., Grossman, S. R., and Androphy, E. J. (2009). The SWI/SNF chromatin remodeling subunit BRG1 is a critical regulator of p53 necessary for proliferation of malignant cells. Oncogene 28 , 2492-2501. doi: 10.1038/onc.2009.121

Nakayama, R. T., Pulice, J. L., Valencia, A. M., McBride, M. J., McKenzie, Z. M., Gillespie, M. A., et al. (2017). SMARCB1 is required for widespread BAF complex-mediated activation of enhancers and bivalent promoters. Nat. Genet. 49, 1613-1623. doi: $10.1038 /$ ng. 3958

Pal, S., Vishwanath, S. N., Erdjument-Bromage, H., Tempst, P., and Sif, S. (2004). Human SWI/SNF-associated PRMT5 methylates histone H3 arginine 8 and negatively regulates expression of ST7 and NM23 tumor suppressor genes. Mol. Cell. Biol. 24, 9630-9645. doi: 10.1128/mcb.24.21.9630-9645.2004

Park, S. J., Kim, J. G., Son, T. G., Yi, J. M., Kim, N. D., Yang, K., et al. (2013). The histone demethylase JMJD1A regulates adrenomedullin-mediated cell proliferation in hepatocellular carcinoma under hypoxia. Biochem. Biophys. Res. Commun. 434, 722-727. doi: 10.1016/j.bbrc.2013.03.091

Pejnovic, N. N., Pantic, J. M., Jovanovic, I. P., Radosavljevic, G. D., Milovanovic, M. Z., Nikolic, I. G., et al. (2013). Galectin-3 deficiency accelerates high-fat dietinduced obesity and amplifies inflammation in adipose tissue and pancreatic islets. Diabetes Metab. Res. Rev. 62, 1932-1944. doi: 10.2337/db12-0222

Ptashne, M. (2007). On the use of the word 'epigenetic'. Curr. Biol. 17, R233-R236. doi: 10.1016/j.cub.2007.02.030

Ptashne, M. (2013). Epigenetics: core misconcept. Proc. Natl. Acad. Sci. U.S.A. 110, 7101-7103. doi: 10.1073/pnas.1305399110

Reisman, D., Glaros, S., and Thompson, E. A. (2009). The SWI/SNF complex and cancer. Oncogene 28, 1653-1668.

Sandhir, R., Halder, A., and Sunkaria, A. (2017). Mitochondria as a centrally positioned hub in the innate immune response. Biochim. Biophys. Acta Mol. Basis Dis. 1863, 1090-1097. doi: 10.1016/j.bbadis.2016.10.020 
Sciacchitano, S., Lavra, L., Morgante, A., Ulivieri, A., Magi, F., De Francesco, G. P., et al. (2018). Galectin-3: one molecule for an alphabet of diseases, from A to Z. Int. J. Mol. Sci. 19:E379. doi: 10.3390/ijms19020379

Sepulveda, H., Aguilar, R., Prieto, C. P., Bustos, F., Aedo, S., Lattus, J., et al. (2017a). Epigenetic Signatures at the RUNX2-P1 and Sp7 Gene Promoters Control Osteogenic Lineage Commitment of Umbilical Cord-Derived Mesenchymal Stem Cells. J. Cell. Physiol. 232, 2519-2527. doi: 10.1002/jcp.25627

Sepulveda, H., Villagra, A., and Montecino, M. (2017b). Tet-Mediated DNA Demethylation Is Required for SWI/SNF-Dependent Chromatin Remodeling and Histone-Modifying Activities That Trigger Expression of the Sp7 Osteoblast Master Gene during Mesenchymal Lineage Commitment. Mol. Cell. Biol. 37:e0177-17. doi: 10.1128/MCB.00177-117

Shafabakhsh, R., Aghadavod, E., Ghayour-Mobarhan, M., Ferns, G., and Asemi, Z. (2019). Role of histone modification and DNA methylation in signaling pathways involved in diabetic retinopathy. J. Cell. Physiol. 234, 7839-7846. doi: $10.1002 /$ jcp. 27844

Shao, J., Weng, X., Zhuo, L., Yu, L., Li, Z., Shen, K., et al. (2019). Angiotensin II induced CSF1 transcription is mediated by a crosstalk between different epigenetic factors in vascular endothelial cells. Biochim. Biophys. Acta Gene. Regul. Mech. 1862, 1-11. doi: 10.1016/j.bbagrm.2018.10.001

Sohn, D. H., Lee, K. Y., Lee, C., Oh, J., Chung, H., Jeon, S. H., et al. (2007). SRG3 interacts directly with the major components of the SWI/SNF chromatin remodeling complex and protects them from proteasomal degradation. J. Biol. Chem. 282, 10614-10624. doi: 10.1074/jbc.M610563200

Stern, P. H., Furukawa, T., and Brody, T. M. (1965). Rat liver and plasma lipids after carbon tetrachloride administration. J. Lipid Res. 6, 278-286.

Strazzabosco, M., Fiorotto, R., Cadamuro, M., Spirli, C., Mariotti, V., Kaffe, E., et al. (2018). Pathophysiologic implications of innate immunity and autoinflammation in the biliary epithelium. Biochim. Biophys. Acta Mol. Basis Dis. 1864(4 Pt B), 1374-1379. doi: 10.1016/j.bbadis.2017.07.023

Tan, L., and Shi, Y. G. (2012). Tet family proteins and 5-hydroxymethylcytosine in development and disease. Development 139, 1895-1902. doi: 10.1242/dev. 070771

Tian, W., Xu, H., Fang, F., Chen, Q., Xu, Y., and Shen, A. (2013). Brahmarelated gene 1 bridges epigenetic regulation of proinflammatory cytokine production to steatohepatitis in mice. Hepatology 58, 576-588. doi: 10.1002/ hep. 26207

Venkatraman, A., Hardas, S., Patel, N., Singh Bajaj, N., Arora, G., and Arora, P. (2018). Galectin-3: an emerging biomarker in stroke and cerebrovascular diseases. Eur. J. Neurol. 25, 238-246. doi: 10.1111/ene.13496

Visentin, M., Lenggenhager, D., Gai, Z., and Kullak-Ublick, G. A. (2018). Druginduced bile duct injury. Biochim. Biophys. Acta Mol. Basis Dis. 1864(4 Pt B), 1498-1506. doi: 10.1016/j.bbadis.2017.08.033

Weng, X., Zhang, Y., Li, Z., Yu, L., Xu, F., Fang, M., et al. (2019). Class II transactivator (CIITA) mediates IFN-gamma induced eNOS repression by enlisting SUV39H1. Biochim. Biophys. Acta Gene. Regul. Mech. 1862, 163-172. doi: 10.1016/j.bbagrm.2019.01.005

Wu, H., Gordon, J. A., Whitfield, T. W., Tai, P. W., van Wijnen, A. J., Stein, J. L., et al. (2017). Chromatin dynamics regulate mesenchymal stem cell lineage specification and differentiation to osteogenesis. Biochim. Biophys. Acta Gene. Regul. Mech. 1860, 438-449. doi: 10.1016/j.bbagrm.2017.01.003

Wu, Q., Lian, J. B., Stein, J. L., Stein, G. S., Nickerson, J. A., and Imbalzano, A. N. (2017). The BRG1 ATPase of human SWI/SNF chromatin remodeling enzymes as a driver of cancer. Epigenomics 9, 919-931. doi: 10.2217/epi-2017-2034
Xiao, C., Gao, L., Hou, Y., Xu, C., Chang, N., Wang, F., et al. (2016). Chromatinremodelling factor Brg1 regulates myocardial proliferation and regeneration in zebrafish. Nat. Commun. 7:13787. doi: 10.1038/ncomms13787

Yamada, D., Kobayashi, S., Yamamoto, H., Tomimaru, Y., Noda, T., Uemura, M., et al. (2012). Role of the hypoxia-related gene, JMJD1A, in hepatocellular carcinoma: clinical impact on recurrence after hepatic resection. Ann. Surg. Oncol. 19(Suppl 3), 355-364. doi: 10.1245/s10434-011-1797-x

Yang, Y., Li, X., Peng, L., An, L., Sun, N., Hu, X., et al. (2018). Tanshindiol C inhibits oxidized low-density lipoprotein induced macrophage foam cell formation via a peroxiredoxin 1 dependent pathway. Biochim Biophys Acta Mol Basis Dis 1864, 882-890. doi: 10.1016/j.bbadis.2017.12.033

Yang, Y., Liu, L., Fang, M., Bai, H., and Xu, Y. (2019a). The chromatin remodeling protein BRM regulates the transcription of tight junction proteins: implication in breast cancer metastasis. Biochim. Biophys. Acta Gene. Regul. Mech. 1862, 547-556. doi: 10.1016/j.bbagrm.2019.03.002

Yang, Y., Liu, L., Li, M., Cheng, X., Fang, M., Zeng, Q., et al. (2019b). The chromatin remodeling protein BRG1 links ELOVL3 trans-activation to prostate cancer metastasis. Biochim. Biophys. Acta Gene. Regul. Mech. 1862, 834-845. doi: 10.1016/j.bbagrm.2019.05.005

Yildirim, O., Li, R., Hung, J. H., Chen, P. B., Dong, X., Ee, L. S., et al. (2011). Mbd3/NURD complex regulates expression of 5-hydroxymethylcytosine marked genes in embryonic stem cells. Cell 147, 1498-1510. doi: 10.1016/j.cell. 2011.11.054

Yu, L., Li, Z., Fang, M., and Xu, Y. (2017). Acetylation of MKL1 by PCAF regulates pro-inflammatory transcription. Biochim. Biophys. Acta Gene. Regul. Mech. 1860, 839-847. doi: 10.1016/j.bbagrm.2017.05.006

Yu, L., Yang, G., Zhang, X., Wang, P., Weng, X., Yang, Y., et al. (2018). Megakaryocytic Leukemia 1 (MKL1) Bridges Epigenetic Activation of NADPH Oxidase in Macrophages to Cardiac Ischemia-Reperfusion Injury. Circulation 138, 2820-2836. doi: 10.1161/CIRCULATIONAHA.118.035377

Zeng, S., Wu, X., Chen, X., Xu, H., Zhang, T., and Xu, Y. (2018). Hypermethylated in cancer 1 (HIC1) mediates high glucose induced ROS accumulation in renal tubular epithelial cells by epigenetically repressing SIRT1 transcription. Biochim. Biophys. Acta Gene. Regul. Mech. 1861, 917-927. doi: 10.1016/j. bbagrm.2018.08.002

Zhang, X., Liu, S., Weng, X., Wu, T., Yu, L., Xu, Y., et al. (2018). Brg1 trans-activates endothelium-derived colony stimulating factor to promote calcium chloride induced abdominal aortic aneurysm in mice. J. Mol. Cell Cardiol. 125, 6-17. doi: 10.1016/j.yjmcc.2018.10.012

Zhang, Y., Yuan, Y., Li, Z., Chen, H., Fang, M., Xiao, P., et al. (2019). An interaction between BRG1 and histone modifying enzymes mediates lipopolysaccharideinduced proinflammatory cytokines in vascular endothelial cells. J. Cell Biochem. 120, 13216-13225. doi: 10.1002/jcb.28595

Conflict of Interest: The authors declare that the research was conducted in the absence of any commercial or financial relationships that could be construed as a potential conflict of interest.

Copyright (C) 2019 Li, Lv, Dai, Wang, Jiang, Fang and Xu. This is an open-access article distributed under the terms of the Creative Commons Attribution License (CC BY). The use, distribution or reproduction in other forums is permitted, provided the original author(s) and the copyright owner(s) are credited and that the original publication in this journal is cited, in accordance with accepted academic practice. No use, distribution or reproduction is permitted which does not comply with these terms. 